\title{
Modelling of Water and Nutrient Distribution Under Micro-Irrigation
}

\author{
Rohitashw Kumar* \\ College of Agricultural Engineering and Technology, Sher-e-Kashmir University of Agricultural \\ Sciences and Technology of Kashmir, India
}

ISSN: 2637-7659

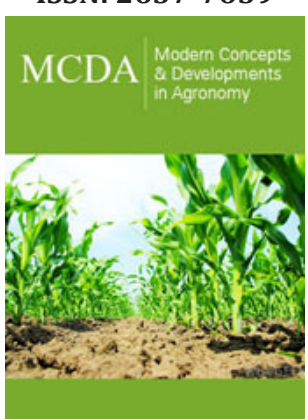

*Corresponding author: Rohitashw Kumar, Professor, College of Agricultural Engineering and Technology, Sher-eKashmir University of Agricultural Sciences and Technology of Kashmir, Srinagar190025, India

Submission: 望 September 24, 2019

Published: 㘹December 03, 2019

Volume 5 - Issue 3

How to cite this article: Rohitashw Kumar. Modelling of Water and Nutrient Distribution Under MicroIrrigation. Mod Concep Dev Agrono.5(3). MCDA.000614.2019.

DOI: 10.31031/MCDA.2019.05.000615

Copyright@ Rohitashw Kumar, This article is distributed under the terms of the Creative Commons Attribution 4.0 International License, which permits unrestricted use and redistribution provided that the original author and source are credited.

\begin{abstract}
This paper presents the review of water and nutrient distribution in crop under micro irrigation. Water and nutrient application under micro-irrigation gives farmers the ability to use crop inputs more effectively and precisely. More effective use of inputs means greater crop yield and/or quality, without polluting the environment. Micro irrigation can address both economic and environmental issues that surround production agriculture today. It is clearly indicated that drip irrigation requires less irrigation water with increased irrigation efficiency and ensure uniform distribution of water and fertilizers as compared to conventional methods. Fertigation also increases the fertilizer use efficiency, which leads to increase in yield and income. The right combination of water and nutrients is the key factor for high yield and the quality of produce.
\end{abstract}

\section{Introduction}

A well-designed fertigation and irrigation system can reduce water and fertilizer application costs considerably, and supply nutrients in precise and uniform amounts to the wetted irrigation zone around the tree where the active feeder roots are concentrated. Applying timely doses of small amounts of nutrients to the trees throughout the growing season has significant advantages over conventional fertilizer practices. Drip irrigation is one of the advanced technologies and innovative method of irrigation that delivers water and nutrients in small quantities and frequent doses directly to crop root zone with a high uniformity of water and fertilizer application. The agricultural land is getting squeezed due to population growth and industrialization. Micro-irrigation has several advantages over other irrigation methods as it does not wet the foliage and because of its high-water application frequency, concentration of salts in the rooting zone remains manageable. Drip irrigation system has gained wide popularity in areas of acute water scarcity and in areas where horticultural crops are grown. In the world scenario, almost $54 \%$ of the drip irrigation is applied to fruit orchard and vegetable crops. This technology was introduced in early seventies in India, but its large-scale adoption started from the eighties particularly in fruit and vegetable crops. In India almost 1.5 lakh hectares of fruit crops and 2.5 lakh hectares of vegetable crops are being added annually under drip irrigation. As per the estimate of Ministry of Agriculture, GOI about 27 million ha in the country has the potential to be brought under drip irrigation. Under drip fertigation, the spatial distribution of soil moisture and consequently crop root zone is restricted to a small volume of soil directly below emitter. Studies carried out worldwide indicate that fertilizer savings through drip fertigation can be in the range of 25 to 30 per cent. Appropriate design of drip fertigation system requires detailed knowledge of water and nutrient distribution pattern in the root zone, nutrient availability in the vicinity of roots and nutrient leaching below the root zone which is the function of discharge of emitter and soil hydraulic and physical properties. Major objectives of the design of drip irrigation system are to control the quantity of water passing though the root zone by regulating the emitter discharge or selecting appropriate size of the emitter, minimizing deep percolation, leaching of nutrients beyond the root zone and keeping the water and nutrients distribution near to the roots. Hydraulic properties of the soils play a critical role in water and nutrient distribution 
in the soil. In design of drip irrigation systems, the volume of soil wetted by single emitter is important.

This must be known in order to determine the total number of emitters required to irrigate the volume of soil to a level that plants do not suffer from water stress. The volume of soil wetted by an emitter is primarily a function of soil texture, soil structure, emitter discharge and the total amount of water applied. Though some guidelines are available to install, maintain and operate drip irrigation systems, there are no clear guidelines for design and managing drip irrigation systems that account for differences in soil hydraulic properties. Conducting field experiments in large number of soils with varying emitter discharge rates to investigate water and nutrient distribution for evolving appropriate design and management option is a costly and time-consuming affair. A properly calibrated and validate flow and solute transport model can reduce time and cost required for studying the water and nutrient dynamics under drip irrigation system. Flow and solute transport models could simulate the water and nutrient distribution in the soil. These models provide an understanding of the relationship amongst the amount and timing of water and nutrient application, the crop root uptake, yield and soil hazard and groundwater pollution (Antonopoules, 2001). However, selection of an appropriate model is very important.

Several models have been developed to simulate water flow, nutrient transport, heat flux, crop water and nutrient uptake and biological transformation of nutrients in the soil (Bergstrom et aI., 1991; Huston and Wagenet, 1991; Jarvis, 1995; Gabriella and Kengni, 1996; Breve et al. 1997; Lafolie et al., 1997). Water and solute transport models enrich the understanding of their movement in the soils and nutrient uptake by plants and can be valuable tools in designing drip fertigation system. Several models have been used for simulating the water and nutrient movement in drip fertigation system. However, most of these models describe the early stage of infiltration and provide an estimate of water content behind the wetting front (Clothier and Scotter, 1982). Although they are easy to implement, they deal mainly with design considerations of the drip source (Cote et al. 2003). Analytical solutions of transient symmetrical infiltration (Warrick, 1974; Revol et al, 1997) can simulate the dynamic condition associated with the drip irrigation but their application was limited in simulation of water and nutrient movement under drip fertigation system under simple boundary conditions. Numerical solution of water and solute transport equations can be an effective tool for Simulating the time dependent flux and other boundary conditions. These solutions can implement wide range of boundary conditions, irregular boundary and soil variability. Development of design and management options for drip fertigation systems involves study of water and nutrient dynamics using an appropriate model under different boundary conditions including flux, no-flux and free drainage boundary. Many studies have been carried out to investigate the water and nutrient distribution under drip irrigation with or without crops.

These studies need to be extended to include field experimental data and modelling to develop different operational scenarios leading to appropriate operation and management options. However, before using a model for simulating water and nutrient distribution, it needs to be calibrated with observed field data. Fertigation is the process of application of soluble fertilizer along with irrigation. Fertigation under drip irrigation is being used commonly for the application of nitrogenous fertilizers in all fruits and vegetable crops. Many research studies have been carried out for the crop response under drip fertigation. Fertigation management is aimed at maximizing growers. income and minimizing environmental pollution. Attaining these objectives depends on economic factors (input costs and produce value) and on crop growth, yield, and fruit quality. The fertigation allows to apply the nutrients exactly and uniformly only to the root volume, where the active roots are concentrated. This remarkably increases efficiency in the application of the fertilizer, which allows reducing the amount applied fertilizer. This not only reduces the production costs but also lessens the potential of groundwater pollution caused by the fertilizer leaching.

\section{Advantage of fertigation are}

A. the saving of energy and labor,

B. the flexibility of the moment of the application (nutrients can be applied to the soil crop or soil conditions would otherwise prohibit entry into the field with convert equipment),

C. convenient use of compound and ready-mix nutrient solutions containing also small concentrations of micronutrients which are otherwise very difficult to apply accurately to the soil, and

D. the supply of nutrients can be more carefully regulated and monitored.

\section{Modelling}

Fertigation Modelling is important for the following reasons

A. It may significantly improve management decision making based on the assumption water, nutrients, and roots uniformly distributed in the wetted soil volume.

B. Mathematical models simulate distribution of water, ions, and roots in soil and calculate uptake from all soil sub-volumes which can improve water and nutrient uptake predictions and provide better estimates of solute leaching outside the soil root volume.

C. Reliable crop-soil-atmosphere models can substitute for expensive field

D. Models stimulate crop growth, yield, and soil processes in response to given initial conditions, temporal water and nutrient supplies, and climatic conditions may be transformed into management decision models.

E. Very few studies are available on modelling of water distribution under drip system and nutrient movement under drip fertigation. Several models have been used for managing various aspects of fertigation. Models have been developed that determine 
when a critical soil moisture level has been reached, as a criterion for irrigation timing and rate.

\section{Water distribution modelling}

Warrick (1974) analyzed water flow from a point source under drip irrigation using a linearized form of the moisture flow equation. The linearized solutions have been extended to time dependent cases for point sources. In this study Ben-Asher et al. (1978) compared numerical and analytical solutions for water flow from a point source under drip irrigation. The numerical solution was for the nonlinear moisture flow equation and the analytical solution for the corresponding linearized form. The numerical results show a faster response both for wetting and drying. Kaul (1979) extended their study of hydraulics of moisture front advance from point as a function of the elapsed time at different levels of total volume of irrigation water and discharge rates. It was reported that information on the soil moisture distribution characteristics as a function of the elapsed time, rate of water application, volume of water applied and the moisture extraction characteristics of the crop which provide useful criteria on determining the frequency of drip irrigation application. Lockington et al. (1984) found a general formula, which predicted the positions of the two water fronts by optimization. It was observed that for particular soil properties the exact numerical solution of the diffusion equation can be easily found and is used to check the accuracy of the optimization formula. They also obtained a simple asymptotic solution which compares favorably with the above results in the long-time limit.

The maximum error associated with neglecting gravity is quantified using this solution and proves to be quite acceptable for most practical applications. Bresler (1978) considered drip irrigation as transient and steady axis-symmetric infiltration process and used an existing numerical solution to non-steady state infiltration to quantify the effect of soil hydraulic properties and drip discharge rates on emitter spacing. The results of the analysis suggested the possibility of controlling the wetted volume of a soil by regulating the emitter discharge according to soil properties. The surface distribution of a transformed soil water content function is derived from a linearized solution to steady infiltration. The analysis of steady and non-steady infiltration is employed to estimate the spacing between as a function of discharge and water pressure conditions between emitters using hydraulic soil data. A soil water dynamics model for establishing the wetting pattern of point source drip emitters under a tomato crop has been developed and verified by Lubana and Narda (1998). Infiltration from the point source drip emitters was investigated in the presence of water extraction by assuming a hemispherical shape of the wetted soil volume and derived for determining the position of wetting front. In that investigation daily values of water uptake were used to uptake the volumetric moisture content in the root zone layers. The values of soil moisture content predicted by the model compared well with the field observed values. The predicted values were used to predict the radius of the hemispherical wetted soil volume which forms a basis for deciding emitter spacing for various crops and operating conditions.

\section{Water and nutrient transport modelling}

Selim and Iskandar (1981) developed a numerical model to simulate water and nitrogen transport and transformation through water-unsaturated, multiplayer soil profiles. Plant uptakes of water and nitrogen were also included. They used an explicitimplicit finite difference approximation method to solve the nitrogen transport and transformation equation with the water flow equation. The model evaluation and sensitivity analysis were carried out for a wide range of values for the rate of nitrification, distribution coefficient for ammonium exchange, and rate of $\mathrm{N}$ uptake. Clothier (1984) developed a theory of solute transport from drip emitters. The model of solute flow was based on piston displacement travel times and steady three-dimensional water flow from a surface point source.

The developed model can be extended to describe the convective transport of absorbed solutes in three dimensions using linear model. Lafolie et al. (1997) studied modelling of water and nitrogen dynamics in irrigated salad crops. The crops were planted on punched and permeable plastic mulching bands. The field was irrigated with a sprinkler watering system. The Richards' equation (one-dimensional) was used for describing saturated- unsaturated water flow in soil. At the soil surface, the model is designed to handle flux-type or imposed pressure boundary conditions. The results showed that the overall trend of the water potential in the soil profile was correctly described during the crop seasons. Mineralization was high for the spring crop, whereas other sink components, such as root uptake, drainage, and denitrification, were smaller. Nitrogen transport during drip fertigation with urea has been presented by Clothier and Sauer (1988). They used an analytical solution for soil wetting from a surface dripper to provide the transient water content profile. The penetration of nitrate evolved from the urea was reasonably well predicted. Water and solute movement in the course of the irrigation cycle and during the subsequent redistribution are considered.

\section{Modelling of water and nutrient distribution}

Modelling has importance of the water and nutrient distribution, there have been various studies conducted over the past decades. Some of these are given as follows:

Lafolie [1] presented a model which was oriented towards the simulation of transport processes rather than biological processes. The simulations resulted the effects of different plant water uptake modelling approaches on water distribution. The study highlighted some of the weaknesses of mechanistic models for predicting water flow. The study compared simulation results with field data to illustrate the degree to which the model was able to predict water flow, solute transport and plant water uptake. The root water potential optimization model which provide the best prediction of water distribution. 
Simunek et al. [2] developed SWMS-2D code for simulating water flow and solute transport in two dimensional variably saturated media. The model solved the Richard's equation for saturated-unsaturated water flow and convection-dispersion equation for solute transport. The flow equation incorporates a sink term to account for water uptake by plant roots. The transport equation includes provisions for liners equilibrium adsorption, zero-order production and first order degradation. Simunek et al. [3] developed the HYDRUS-2D software package for simulating two-dimensional movement of water, heat and multiple solute in variably saturated soil. The software package consists of the HYDRUS-2D computer program and plotted interactive graphicsbased user interface HYDRUS-2D. The HYDRUS-2D program numerically solves the Richard's equation for saturated unsaturated water flow for solute transport. The flow equation incorporates a sink term for root water by plant roots. The HYDRUS-2D can used flow regions delineated by irregular boundaries.

A review study of water and solute dynamics under drip irrigated crop was done by Mmolawa \& Or D [4]. It was concluded that water and solute dynamics largely depended on the root distribution and activity of plants as well as nutrient being introduced in the soil root zone. Roots are responsible for creating gradients in the soil water potential and in the nutrient concentration. It happened due to water and solute movement along these gradients by mass flow and diffusion. A simulation model FUSSIM2 was developed by Heinen [5] for drip fertigation to study various fertigation scenarios. In this study, water movement was presented using Richard's equation with the constitutive relationships given by the Van Genuchten and Mualem functions. The Richard's equation was solved using the control volume finite element method. The solute dynamics described using convective-dispersive process equation and was explicitly solved. The analysis was carried out with alternative fertigation strategies which can reduces the number of field experiments. Assouline [6] compared the effect of three emitter discharges, $0.25,2.0$ and $8 \mathrm{lh}^{-1}$, on different aspect of the water regime in daily drip irrigated corn.

In this study field observation indicated that micro-drip irrigation

I. tends to increase yield although this was not statistically significant under the experimental conditions,

II. induces higher relative water content in the 0 to $0.30 \mathrm{~m}$ depth layer, and lower ones in the 0.60 to $0.90 \mathrm{~m}$ layer.

Numerical simulations using HYDRUS-2D simulation model, indicated that micro drip irrigated field led to smallest wetted volume with the least extreme water content gradient both in the horizontal and vertical axes. Bristow et al. [7] used the HYDRUS-2D to evaluate impacts of soil properties, soil profile feature (layering, and change management practices on water and solute transport) in buried trickle irrigation systems. The study revealed that by changing the fertigation strategy to involve application of nonadsorbed mobile nutrients at the beginning of an irrigation cycle rather than near the end of the cycle, larger amounts of nutrients could be maintained near to and above the drip emitter. Li et al.
[8] conducted investigation the effects of fertigation strategies on wetting patterns and nitrogen distribution in the soil from surface point source of nitrate ammonium. Analyses on the effects of application rate on the water distribution pattern demonstrated that increasing the water application rate allows more water to distribute in horizontal direction, while decreasing the rate allows more water to distribute in vertical direction for a given volume applied. An extremely high ammonium concentration existed in the proximity of the point source because ammonium was absorbed by soil. Consequently, fertigation strategy had an insignificant influence on the peak value. Comparative study on HYDRUS-2D simulation of drip irrigation with experimental observations was investigated by Skaggs et al. [9]. In this study a sandy loam soil was irrigated using thin walled drip tubing installed at a depth of $6 \mathrm{~cm}$. At the end of each irrigation and approximately $24 \mathrm{~h}$ later, the water content distribution is found to be in very good agreement with the data. The results support the use of HYDRUS-2D as a tool for investigating and designing drip irrigation management practices. Gardenas et al. [10] conducted experiment to assess the effect of fertigation strategy and soil type on nitrate leaching potential on four different micro-irrigation systems. They found that seasonal leaching was lowest for subsurface drip tape for which water and fertilizers were effectively supplied to the rooting system.

They concluded that the fertigation at the beginning of the irrigation cycle tends to increase seasonal nitrate leaching. A model of water and nitrate transport in soil from a surface point source of ammonium nitrate $\left(\mathrm{NH}_{4} \mathrm{NO}_{3}\right)$ was established and solved numerically by using HYDRUS-2D software. Simulated wetting dimensions of soil volume and distributions of water content and nitrate concentrations in soil were compared with data obtained from laboratory experiments on a loam and a sandy soil (Li et al., 2005). The data demonstrated an excellent agreement between the simulated results and the observed data. Then the verified model was used to simulate water and nitrate distributions under various initial conditions and fertigation strategies. The results demonstrated that nitrate distribution was greatly affected by fertigation strategies. The HYDRUS-2D enabled us to implement water and nitrogen transport under surface drip fertigation and to strengthen the conclusions derived from the observations. The information obtained from the simulations is helpful in the design, operation, and management of a fertigation system with drip irrigation.

Cook et al, [11] developed a software tool (WetUp) to calculate the wetting patterns from trickle irrigation emitters which calculate the wetted perimeter for both buried and surface emitters. Comparison was made with the wetting patterns calculated with a 2-dimensional numerical model; Difficulties were also experienced with getting stable solutions with HYDRUS2-D for soils with low hydraulic conductivities. The observed dynamics of the water content distribution was in good agreement with model simulations, although some discrepancies concerning the horizontal distribution of the irrigation bulb were noted due to soil heterogeneity. Hanson et al. (2006) conducted the study to use an adapted version of the HYDRUS-2D computer model to develop irrigation and fertigation management tools that maximize production, minimize adverse 
environmental effects. The objective of the study was to model the distribution of soil nitrogen and nitrate leaching using a urea-ammonium-nitrate fertilizer. In addition, the distribution of phosphorus and potassium was modeled. The results revealed that the HYDRUS-2D computer simulation model is an effective modeling tool for assessing fertigation strategies using a urea-ammoniumnitrate fertilizer commonly used for fertigation with micro irrigation. The model described the movement of urea, ammonium, and nitrate during irrigation and accounted for the reactions of hydrolysis, nitrification, and ammonium adsorption. The results also showed that urea moves readily with the infiltrating irrigation water, potentially moving this nitrate source away from the soil zone with maximum root density. Patel \& Rajput [12] conducted field experiment for 3 years (1999-2002), HYDRUS-2D was used for simulation of moisture distribution pattern in the root zone of onion crop grown in sandy loam soil. The model performance was evaluated by comparing its simulated value with the observed soil moisture patterns through certain indicators such as average absolute error (AAE), average relative error (ARE) and root mean square error (RMSE). Range of AAE (-5.65 to-2.86), ARE $(0.112$ to 0.147 ) and RMSE (3.58 to 6.10) indicate good match between simulated and observed soil moisture patterns. Rajput \& Patel [13] also carried out field experiment to observe the water movement under three irrigation treatments and $\mathrm{NO}_{3}-\mathrm{N}$ distribution under four fertigation frequencies and their effect on yield of onion crop. Three irrigation levels of 60,80 and $100 \%$ of the crop evapotranspiration (ET) and four fertigation frequencies of daily, alternate day, weekly and monthly comprised the fertigation treatment. Analysis of soil samples indicated considerable influence of fertigation frequency on $\mathrm{NO}_{3}$-N distribution in soil profile.

$\mathrm{NO}_{3}-\mathrm{N}$ in lower soil profiles $(30.0-60.0 \mathrm{~cm}$ soil depth) was marginally affected in daily, alternate day and weekly fertigation. The level of soil $\mathrm{NO}_{3}-\mathrm{N}$ after the crop season showed that more $\mathrm{NO}_{3}-\mathrm{N}$ leached through the soil profile in monthly fertigation frequency. Singh et al. [14] conducted experiment to study the soil wetting pattern with subsurface drip irrigation from line source. Simulation model was used for determining geometry of wetted soil zone under line sources of water application placed below the soil surface. The predicted values of wetted depth and width were compared with those obtained through field experiments conducted under sandy loam soil. Experimentation included determination of maximum depths and widths of wetted zone after $0.5,1,2,3$, 5 , and $7 \mathrm{~h}$ of water application under laterals, porous pipes, and drip tape placed at $0.05,0.10$ and $0.15 \mathrm{~m}$ depths below soil surface. This showed that developed model can be used to simulate wetting pattern under SDI system with line source of water application.

Ajdary et al. [15] evaluated the nitrogen leaching under different fertigation strategies. A two-dimensional solute transport model HYDRUS-2D was applied to simulate the nitrogen leaching from various soils for varying emitter discharge rates and fertigation strategies. The study results revealed that emitter discharge rate did not affect nitrogen distribution in sandy clay loam and loam soils as compared to in sandy loam, silt clay loam and silt soils. Provanzano [16] conducted a field experiment to evaluate the HYDRUS-2D simulation model at the scale of single emitter with the aim to assess the axis symmetrical infiltration process consequent to subsurface drip irrigation. The model was then applied in order to evaluate the main dimensions of the wetted soil volume surrounding the emitter during irrigation as a function of time and initial soil water content. The investigation, carried out in a sandy-loam soil, showed the suitability of the model to well simulate infiltration processes around an emitter during irrigation. Zhou et al. [17] evaluated 2D root water uptake model based on soil water dynamic and root distribution of grapevine, and a function of soil evaporation. The simulated soil water contents by two models were compared with the measured value. The average relative error between the simulated and measured soil water content was about $10 \%$ for APRI-model, and from $11 \%$ to $29 \%$ for HYDRUS-2D model which indicating that two models perform well in simulating soil moisture dynamic which was more suitable for modelling the soil water dynamic in the arid region with greater soil evaporation and uneven root distribution. Arbat et al. [18] conducted a field experiment to calibrate the Hydraulic function of the soil from measurements of soil water content and matric potential. Simulation models, based on the Richards equation, allows the distribution of water in the soil to be determined taking into account the field conditions. In this study, sensor measurements of the soil water content and the soil water potential were used to adjust the hydraulic conditions of the soil by means of inverse calibration techniques. The results show that soil water flow models are capable of being automatically calibrated and are a powerful tool for complementing the information taken by the sensors. Ajdary [19] conducted a study to investigate the nitrogen distribution pattern under sandy loam soil. The study involved field experiment and modelling of nitrogen leaching. Field data were used to calibrate and validate the solute transport model HYDRUS-2D. Three fertigation strategies were considered for the experiment. The results of the study revealed that in sandy loam soil, fertigation strategy is affecting the nitrogen leaching. This study revealed that in case of permeable soils like sandy loam, fertigation strategies play role in leaching.

Elmaloglou \& Diamantopoulos [20] evaluated the model performance in simulating soil water dynamics by comparing the predicted soil water content values with both those of HYDRUS-2D model and an analytical solution for a buried single strip source. Soil water distribution patterns for three soils (loamy sand, silt, silty clay loam) and two discharge rates at four different times were presented. The numerical results showed that the soil wetting pattern mainly depends on soil hydraulic properties; that at a time equal to irrigation duration decreasing the discharge rate of the line sources but maintaining the applied irrigation depth, the vertical and horizontal components of the wetting front were increased; that at a time equal to the total simulation time the discharge rate has no effect on the actual transpiration and actual soil evaporation and a small effect on deep percolation. Elmaloglou et al. [21] conducted experiment to validate the assumption that an irrigation event from point sources can be approximated as an infinite line source. Two existing mathematical models which simulate point and line drip irrigation were used. The comparison was made for two soil types (loamy sand and silt). 
The results indicated that the treatment of a point source as a line source underestimates the water content values for both the soil types. This difference decreases when the depth of comparison increases. For soil depths greater than $30 \mathrm{~cm}$ and for time greater than irrigation duration the two models gave very close results. Kandelous \& Simunek [22] evaluated accuracy of several approaches used to estimate wetting zone dimensions by comparing their predictions with field and laboratory data, including the numerical HYDRUS-2D model, the analytical WetUp software, and selected empirical models [23-25]. The mean absolute error (MAE) was used to compare the model predictions and observations of wetting zone dimensions [26,27]. MAE for different experiments and directions varied from 0.87 and $10.43 \mathrm{~cm}$ for HYDRUS-2D from 1 to $58.1 \mathrm{~cm}$ for WetUp and from 1.34 to $12.24 \mathrm{~cm}$ for other empirical models.

\section{Conclusion}

Modelling of water and nutrient distribution is a difficult task in varying agro climatic region of world. Modelling serve as management decision tool, target yield versus time function. It represents fertigation regime and given climatic conditions, Several models have been used for managing various aspects of fertigation which determine a critical soil moisture level as a criterion for irrigation timing and rate. Mathematical models that simulate distribution of water, ions, and roots in soil and calculate uptake from all soil sub-volumes can improve water and nutrient uptake predictions and provide better estimates of solute leaching outside the soil root volume.

\section{References}

1. Lafolie F (1991) Modelling water flow, nitrogen transport and root uptake including physical non-equilibrium and optimization of the root water potential. Fertil Res 27(2-3): 215-231.

2. Simunek J, Vogel T, van Genuchten MTh (1994) The SWMS-2D code for simulating water flow and solute transport in two-dimensional variably saturated media. Research report No. 132. US Salinity Laboratory Agricultural Research Service, US Department of Agriculture, Reverside, California, USA.

3. Simunek J, Sejna M, van Genuchten MTh (1999) The HYDRUS-2D software package for simulating the two-dimensional movement of water, heat and multiple solute in variably saturated media. International Groundwater Modelling Centre, Colorado School of Mines Golden, USA.

4. Mmolawa K, Or D (2000) Water and solute dynamics under a drip irrigated crop: Experiments and analytical model. Trans ASAE 43(6): $1597-1608$

5. Heinen M (2001) FUSSIM2: Brief description of simulation model and application to fertigation scenarios. Agronomy 21(4): 285-296.

6. Assouline S (2002) The effect of micro drip and conventional drip irrigation on water distribution and uptake. Soil Sci Soc Am J 66(5): $1630-1636$.

7. Bristow KL, Hopmans JW, Cote CM, Charlesworth PB, Thorburn PJ, et al. (2002) Development of improved water and nutrient management strategies through strategic modelling. Symposium no. $54,17^{\text {th }}$ WCSS. Thailand, 1022(1-9).

8. Li J, Zhang J, Rao M (2004) Wetting patterns and nitrogen distributions as affected by fertigation strategies from a surface point source. Agric Water Manage 67(2): 89-104.
9. Skaggs TH, Trout TJ, Simunek J, Shouse J (2004) Comparison of HYDRUS2D simulation of drip irrigation with experimental observations. J Irrig Drain Eng 130(4): 1-7.

10. Gardenas AI, Hopmans JW, Hanson BR, Simunek J (2005) Twodimensional modelling of nitrate leaching for various fertigation scenarios under micro-irrigation. Agric Water Manage 74(3): 219-242.

11. Cook FJ, Fitch P, Thorburn PJ, Charlesworth PB, Bristow KL (2006) Modelling trickle irrigation: Comparison of analytical and numerical models for estimation of wetting front position with time. Environmental Modelling \& Software 21(9): 1353-1359.

12. Patel N, Rajput TBS (2006) Simulation and modeling of moisture distribution in drip irrigated onion. J Agric Engg 43(2): 22-27.

13. Rajput TBS, Patel N (2006) Water and nitrate movement in drip-irrigated onion under fertigation and irrigation treatments. Agric Water Manage 79(3): 293-311.

14. Singh DK, Rajput TBS, Singh DK, Sikarwar HS, Sahoo RN, et al. (2006) Simulation of soil wetting pattern with subsurface drip irrigation from line source. Agric Water Manage 83(1-2): 130-134.

15. Ajdary K, Singh DK, Singh AK, Manoj Khanna (2007) Modeling of nitrogen leaching from experimental onion field under drip fertigation. Agric Water Manage 89(1-2): 15-28.

16. Provanzano G (2007) Using HYDRUS-2D simulation model to evaluate wetted soil volume in subsurface drip irrigation systems. J Irrig Drain Eng 133(4): 342-349.

17. Zhou Q Kang S, Zhang L, Li L (2007) Comparison of APRI and HYDRUS2D models to simulate soil water dynamics in a vineyard under alternate partial root zone drip irrigation. Plant and Soil 291(1-2): 211-223.

18. Arbat G, Puig Bargues J, Barragan J, Bonany J, Ramirezde Cartagena F (2008) Monitoring soil water status for micro-irrigation management versus modeling approach. Biosystems Engineering 100(2): 286-296.

19. Ajdary K (2008) Simulation of nitrogen distribution in soil with drip irrigation system. J Applied Sciences 8(18): 3157-3165.

20. Elmaloglou S, Diamantopoulos E (2009) Simulation of soil water dynamics under subsurface drip irrigation from line sources. Agric Water Manage 96(11): 1587-1595.

21. Elmaloglou S, Diamantopoulos E, Dercas N (2010) Comparing soil moisture under trickle irrigation modelled as a point and line source. Agric Water Manage 97(3): 426-432.

22. Kandelous MM, Simunek J (2010) Comparison of numerical, analytical and empirical models to estimate wetting patterns for surface and subsurface drip irrigation. Irrig Sci 28(5): 435-444.

23. Kumar M, Kumar R (2018) Hydraulics of Water and nutrient application through drip irrigation. A review J Soil and Water Conservation 17(1): 65-74.

24. Mantell A, Frenkel H, Meiri A (1985) Drip irrigation of cotton with salinesodic water. Irrigation Science 6(2): 95-106.

25. Patel N, Rajput TBS (2008) Dynamics and modeling of soil water under subsurface drip irrigated onion. Agric Water Manage 95(12): 13351349.

26. Tukaram SS (2011) Modelling nutrient distribution under drip irrigation in onion crop. PhD Thesis, IARI, New Delhi, India.

27. Wang X, Xing Y (2016) Effects of irrigation and nitrogen fertilizer input levels on soil NO3 (-)-N content and vertical distribution in greenhouse tomato (Lycopersicum esculentum Mill.). Scientifica (Cairo) 2016: 5710915. 